\title{
Impact of an orthogeriatric collaborative care model for older adults with hip fracture in a community hospital setting
}

\author{
Janice C. Lee, MD \\ Kevin Koo, MD \\ Eric K.C. Wong, MD \\ Raza Naqvi, MD, MHSc \\ Camilla L. Wong, MD, MHSc
}

Presented at the 39th Annual Scientific Meeting of the Canadian Geriatrics Society, May 2-4, 2019, Halifax, N.S.

Accepted May 12, 2020

Correspondence to:

C. Wong

30 Bond St

Toronto ON M5B 1W8

camilla.wong@unityhealth.to

DOI: $10.1503 /$ cjs. 001720

\begin{abstract}
Background: Studies have shown that the incidence of postoperative delirium, the hospital length of stay and time to surgery are reduced when older adults with a hip fracture are cared for by a multidisciplinary team providing comprehensive geriatric assessments. Most of these studies have been conducted in academic centres. We sought to determine if implementation of an orthogeriatric collaborative care model would improve key quality of care metrics in a community hospital setting.

Methods: This retrospective pre- and postintervention single-site study was conducted in a community hospital in Ontario, Canada. We included consecutive patients aged 65 years or older who were admitted for a hip fracture between June 2015 and June 2017. In the intervention period, a new postoperative order set included a referral to a geriatrician for comprehensive geriatric assessment, with direct implementation of recommendations. Primary outcomes were the incidence of postoperative delirium and length of stay. Secondary outcomes included Health Quality Ontario's quality standards for hip fracture.
\end{abstract}

Results: A total of 212 consecutive patients (95 in the preintervention group and 117 in the postintervention group) were included in the study. The incidence of postoperative delirium $(26.3 \%$ v. $26.5 \%, p=0.98)$ and length of stay (interquartile range $4-10$ v. $5-10 \mathrm{~d}, p=0.32$ ) were similar in the preintervention and postintervention groups. There were improvements $(p<0.001)$ in the rates of asssessment of mental status, falls and bone health; identification of delirium prevention strategies; prescription of vitamin D or calcium or both; and recommendations for antiresorptive therapy. Despite systemic implementation of the orthogeriatric model, only $74.4 \%$ of patients in the postintervention group were seen by a geriatric medicine consultant.

Conclusion: Although the implementation of an orthogeriatric collaborative care model for older adults with a hip fracture did not reduce the incidence of postoperative delirium or length of stay, there were improvements in the rates at which several other key quality standards for hip fracture care were met. Earlier proactive, comprehensive geriatric assessment in a community hospital setting will be the target for further quality improvement initiatives.

Contexte : Des études ont montré que l'incidence du délire postopératoire, la durée du séjour à l'hôpital et le temps d'attente avant la chirurgie sont réduits lorsque les personnes âgées présentant une fracture de la hanche reçoivent les soins d'une équipe multidisciplinaire qui réalise une évaluation gériatrique complète. La plupart de ces études ont été effectuées dans des centres universitaires. Nous souhaitions donc déterminer si l'intégration d'un modèle de soins orthogériatriques collaboratif améliorerait les principaux indicateurs de la qualité des soins dans les hôpitaux communautaires.

Méthodes : Cette étude rétrospective comparant 2 groupes de patients avant et après la mise en œuvre d'une intervention a été menée dans un seul hôpital communautaire en Ontario, au Canada. Nous avons inclus les patients consécutifs de 65 ans et plus admis pour une fracture de la hanche entre juin 2015 et juin 2017. Pendant la période d'intervention, un nouvel ensemble d'ordonnances postopératoires a été ajouté. Il comprenait l'aiguillage vers un gériatre pour une évaluation gériatrique complète et l'application directe des recommandations. Les principales issues à l'étude étaient l'incidence du délire postopératoire et la durée de l'hospitalisation. Les issues secondaires comprenaient le respect des normes de qualité relatives à la fracture de la hanche de Qualité des services de santé Ontario.

Résultats : Au total, 212 patients consécutifs ( 95 dans le groupe préintervention et 117 dans le groupe postintervention) ont été inclus dans l'étude. L'incidence du délire postopératoire ( $26,3 \%$ c. $26,5 \%, p=0,98)$ et la durée de l'hospitalisation (écart interquartile 4-10 jours c. 5-10 jours, $p=0,32$ ) étaient similaires dans les 2 groupes. Il y a eu des améliorations $(p<0,001)$ dans le taux d'évaluation de l'état mental, des chutes 
et de la santé des os; dans l'intégration de stratégies de prévention du délire; dans la prescription de vitamine $\mathrm{D}$ ou de calcium, ou des deux; et dans les recommandations de traitement antirésorptif. Malgré l'adoption du modèle orthogériatrique dans l'ensemble du centre, seulement $74,4 \%$ des patients du groupe postintervention ont eu une consultation en gériatrie.

Conclusion : Bien que la mise en œuvre d'un modèle de soins orthogériatriques collaboratif chez les personnes âgées présentant une fracture de la hanche n'ait pas réduit l'incidence du délire postopératoire ou la durée de l'hospitalisation, il y a eu une amélioration du respect de plusieurs normes de qualité importantes relatives à ce type de fracture. L'évaluation gériatrique complète réalisée tôt, de manière proactive, dans les hôpitaux communautaires sera la cible d'initiatives d'amélioration de la qualité à venir.

A s Canadians are living longer lives, hospitals are managing an increasing number of patients with hip fractures each year. In the province of Ontario, the number of hip fractures increased from 7725 in $2005 / 06$ to 8242 in $2014 / 15$, including a $9 \%$ increase among adults aged 80 years and older. ${ }^{1}$ There is substantial morbidity and mortality associated with hip fractures in older adults; 30-day mortality rates in 2014/15 ranged from $3 \%$ to $17 \%$ across Ontario hospitals. ${ }^{2}$ International and national guidelines on the management of hip fractures published over the last decade have emphasized not only timeliness of surgery and quality standards of surgical management but also rigorous orthogeriatric assessment and multidisciplinary care. ${ }^{3-7}$

Studies have shown that dedicated orthogeriatric services including geriatric medicine and multidisciplinary support for this population reduced mortality, ${ }^{8-11}$ decreased length of hospital stay, ${ }^{8,9}$ reduced incidence of postoperative delirium ${ }^{12}$ and improved postoperative mobility. ${ }^{13}$ Broadly speaking, there are several models of orthogeriatric care, including (1) orthopedic units with geriatric consultations on request, (2) orthopedic wards with shared care by geriatricians and (3) geriatric medicine units with orthopedic consultants. At the heart of geriatric care is the comprehensive geriatric assessment (CGA), which is a multidimensional interdisciplinary diagnostic process focused on determining a frail older adult's medical, psychological and functional capability so that a coordinated and integrated plan can be developed for treatment and long-term follow-up. ${ }^{14}$ Proactive CGAs in older adults with hip fracture are now often standard practice in large regional hospitals, where there is systemic implementation of early CGAs to address geriatric syndromes and direct application of recommendations in their care. ${ }^{15}$ Although there is uncertainty on the optimal timing of CGAs, ${ }^{16}$ a randomized controlled trial in older adults with hip fracture found a reduction in the incidence of delirium and the severity of delirium after implementation of proactive geriatric consultation preoperatively or within 24 hours postoperatively. ${ }^{17}$

A 2016 Canadian study at a Toronto academic centre demonstrated reduced length of stay, reduced costs, decreased time to surgery and increased initiation of osteoporosis treatment after an integrated hip fracture comanagement model with hospitalists and geriatric subspecialty services was implemented. ${ }^{18}$ Most studies on the impact of orthogeriatric collaboration in the treatment of patients with hip fracture have been conducted in large academic centres. These hospitals often have robust support from larger teams of orthopedic surgeons, internists and geriatricians, not to mention patient coverage on evenings, weekends and holidays by house staff and trainees. It is unclear whether the positive outcomes seen in the studies in large centres can be generalized to community hospital settings, which often do not have the same workforce structure.

The objective of this study was to determine whether the implementation of an orthogeriatric collaborative care model in a community hospital would have similar positive impacts on patient care and outcomes such as incidence and duration of delirium, hospital length of stay and mortality. A secondary aim of this study was to determine whether this orthogeriatric collaboration would improve the rate at which the hospital met various quality standards of hip fracture care as outlined by Health Quality Ontario, the organization that advises the province of Ontario on health care quality. ${ }^{2}$ Health Quality Ontario's role includes translation of evidence into quality standards and reporting on health system performance across the province.

\section{Methods}

\section{Study design and setting}

This was a single-site retrospective pre- and postintervention study of consecutive older adults admitted with hip fracture to a community hospital. Markham Stouffville Hospital (MSH) is a 200-bed community hospital in Ontario, Canada, with an affiliated 20-bed partner site. In July 2016, MSH established a new orthogeriatric collaborative care model between the orthopedic surgery and geriatric medicine services for older adults admitted with hip fracture.

\section{Participants}

We included adults aged 65 years or older consecutively admitted to the orthopedics service with an admitting diagnosis of a hip fracture between June 1, 2015, and 
June 30, 2017. Patients with multiple fractures, nonfragility fractures or periprosthetic fractures, patients admitted on an elective basis and patients transferred in from other institutions were excluded.

\section{Intervention}

The preintervention period was from June 1, 2015, to May 31, 2016. At the time, patients were admitted to the orthopedic ward, with consultations made to geriatric medicine at the discretion of the orthopedic surgeon. Many patients were seen preoperatively by internal medicine consultants to evaluate perioperative risk. However, there was no specific focus on geriatric principles of care. Patients admitted during the month of June 2016 were omitted from the study to account for a geriatrician's transition into practice and implementation of the orthogeriatric care model.

The postintervention period was from July 1, 2016, to June 30,2017 . The goal was to implement proactive geriatric assessment for all older patients with hip fracture. All eligible patients were referred systematically to the geriatric medicine service for a CGA via a newly designed postoperative order set. Although the orthopedic surgeon remained the most responsible physician, the geriatrician implemented care recommendations directly under this new orthogeriatric collaborative care model. There were no changes to the internal medicine service's role in operative risk evaluation.

\section{Data abstraction}

Potential participants for this study were identified using the hospital's database on the basis of a diagnosis of hip fracture, including its subtypes. Chart abstraction from electronic medical records was performed by one of the study authors (J.L.), who was not blinded to the study objectives. Uncertainties in data coding were resolved in consultation with a local community geriatrician (R.N.) and an academic geriatrician (C.W.). A validated chartabstraction tool based on the Confusion Assessment Method was used to detect delirium. ${ }^{19}$ A detailed chart abstraction guideline for each variable is outlined in Appendix 1 (available at canjsurg.ca/001720-a1).

\section{Outcomes}

The primary outcomes were hospital length of stay (total number of days admitted to MSH in acute care) and the incidence of postoperative delirium. Secondary outcomes included key process and outcome metrics for hip fracture care as outlined in Health Quality Ontario's Quality-Based Procedures: Clinical Handbook for Hip Fracture. ${ }^{2}$ These included time to surgery, use of a standing order for acetaminophen, use of peripheral nerve blocks, identification of delirium prevention strategies, osteoporosis assessment, mental status assessment, falls assessment, delirium duration, discharge destination, prescription for vitamin $\mathrm{D}$ or calcium or both, initiation of antiresorptive therapy, in-hospital mortality, in-hospital urinary tract infection, hospital-acquired pneumonia, thromboembolism and acute coronary syndrome.

\section{Statistical analysis}

Data were reported as means with standard deviations (SDs) for continuous descriptive variables, as medians with interquartile ranges (IQRs) if the data were skewed, or as proportions for categorical variables. The $\chi^{2}$ test was used to assess differences in categorical variables. Multivariable logistic regression was used to adjust for factors associated with the outcomes of interest. Predictor variables were chosen a priori by the investigators on the basis of factors known to increase the risk of the primary outcomes (length of stay and incidence of delirium). The model for delirium included age, intraoperative nerve block, type of anesthesia, Charlson Comorbidity Index (CCI) score ${ }^{20}$ and requirement for an intensive care unit (ICU) stay. The model for length of stay included age, CCI score, requirement for an ICU stay, transfer from the hospital's partner site, and place of residence. Statistical significance was defined at $p<0.05$. All variables were tested for multicollinearity. Model fit was tested using the Hosmer-Lemeshow test and model discrimination was assessed using the C statistic. Analyses were conducted using SAS version 9.4 (SAS Institute Inc.).

\section{Results}

A total of 212 consecutive patients aged 65 years or older admitted for a hip fracture to MSH during the study period were included in the study. There were 95 patients in the preintervention group and 117 patients in the postintervention group. The baseline patient characteristics in the 2 groups were similar, except that more intraoperative nerve blocks were performed during the postintervention period (Table 1).

After the orthogeriatric collaborative care model was implemented, the percentage of patients who received geriatric consultations had increased from $28.4 \%$ to $74.4 \%$. The incidence of delirium $(26.3 \%$ v. $26.5 \%, p=$ 0.98 ) and length of stay (median 7.0 v. $7.0 \mathrm{~d}, p=0.32$ ) were similar in the preintervention and postintervention periods. Among patients who exhibited delirium, the duration of delirium did not differ significantly between the groups (Table 2). There was also no difference between the groups in terms of in-hospital mortality, discharge to long-term care from hospital, postoperative urinary tract infection, hospital-acquired pneumonia, postoperative venous thromboembolism or acute 


\begin{tabular}{|c|c|c|c|}
\hline \multirow[b]{2}{*}{ Characteristic } & \multicolumn{2}{|c|}{ No. (\%) of patients* } & \multirow[b]{2}{*}{$\begin{array}{c}p \\
\text { value }\end{array}$} \\
\hline & $\begin{array}{l}\text { Preintervention } \\
\text { group } \\
n=95\end{array}$ & $\begin{array}{c}\text { Postintervention } \\
\text { group } \\
n=117\end{array}$ & \\
\hline Age, yr & & & 0.08 \\
\hline$\leq 75$ & $22(23.2)$ & $17(14.5)$ & \\
\hline $76-85$ & 36 (37.9) & $43(36.8)$ & \\
\hline$\geq 86$ & $37(39.0)$ & $57(48.7)$ & \\
\hline Median (IQR) & 84 (77-89) & 85 (79-90) & \\
\hline Female sex & 74 (77.9) & $89(76.1)$ & 0.75 \\
\hline \multicolumn{4}{|l|}{$\begin{array}{l}\text { Place of residence before } \\
\text { hospital admission }\end{array}$} \\
\hline Home & 81 (85.3) & $95(81.2)$ & 0.73 \\
\hline $\begin{array}{l}\text { Retirement or assisted } \\
\text { living facility }\end{array}$ & $8(8.4)$ & $13(11.1)$ & \\
\hline $\begin{array}{l}\text { Nursing home or } \\
\text { complex care facility }\end{array}$ & $6(6.3)$ & $9(7.7)$ & \\
\hline \multicolumn{4}{|l|}{$\begin{array}{l}\text { Charlson Comorbidity } \\
\text { Index score }{ }^{19}\end{array}$} \\
\hline$\leq 3$ & $12(12.6)$ & $15(12.8)$ & 0.96 \\
\hline $4-5$ & 49 (51.6) & $58(49.6)$ & \\
\hline$\geq 6$ & $34(35.8)$ & $44(37.6)$ & \\
\hline $\begin{array}{l}\text { Preadmission use of } \\
\text { therapeutic anticoagulation }\end{array}$ & $10(10.5)$ & $14(12.0)$ & 0.74 \\
\hline \multicolumn{4}{|l|}{ Type of fracture } \\
\hline Subcapital or intracapsular & $44(46.3)$ & $58(49.6)$ & 0.17 \\
\hline Stable intertrochanteric & $17(17.9)$ & $28(23.9)$ & \\
\hline Unstable intertrochanteric & $26(27.4)$ & $18(15.4)$ & \\
\hline Unstable subtrochanteric & $8(8.4)$ & $13(11.1)$ & \\
\hline \multicolumn{4}{|l|}{ Type of surgery } \\
\hline Total hip arthroplasty & $1(1.1)$ & 0 & 0.61 \\
\hline Hemiarthroplasty & $38(40.0)$ & $42(35.9)$ & \\
\hline $\begin{array}{l}\text { Dynamic hip or } \\
\text { cannulated screws }\end{array}$ & $34(35.8)$ & $43(36.8)$ & \\
\hline Intramedullary nail & $20(21.1)$ & 31 (26.5) & \\
\hline Nonoperative & $2(2.1)$ & $1(0.9)$ & \\
\hline \multicolumn{4}{|l|}{ Type of anesthesia } \\
\hline Regional & $78(83.9)$ & $97(83.6)$ & 0.96 \\
\hline General & $15(16.1)$ & $19(16.4)$ & \\
\hline $\begin{array}{l}\text { Intraoperative nerve } \\
\text { block }\end{array}$ & $76(81.7)$ & $107(92.2)$ & 0.022 \\
\hline
\end{tabular}

coronary syndrome. Time to surgery was unchanged (median 23.6 v. $24.3 \mathrm{~h}, p=0.39$ ).

Implementation of the orthogeriatric model significantly improved the hospital's success in meeting several quality indicators: rates of assessment of mental status, falls and bone health; identification of delirium prevention strategies; prescription of vitamin $\mathrm{D}$ or calcium or both; and recommendations for antiresorptive therapy. There was a trend toward the use of more preoperative nerve blocks in the postintervention group ( $9.5 \%$ v. $18.8 \%, p=0.06)$. The use of scheduled acetaminophen was high in both periods.
Table 2. Process and clinical outcome measures

\begin{tabular}{|c|c|c|c|}
\hline \multirow[b]{2}{*}{ Measure } & \multicolumn{2}{|c|}{ No. $(\%)$ of patients* } & \multirow[b]{2}{*}{$p$ value } \\
\hline & $\begin{array}{l}\text { Preintervention } \\
\text { group }\end{array}$ & $\begin{array}{l}\text { Postintervention } \\
\text { group }\end{array}$ & \\
\hline \multicolumn{4}{|l|}{ Process } \\
\hline $\begin{array}{l}\text { Time to surgery (h), } \\
\text { median (IQR) }\end{array}$ & $23.6(13.7-30.6)$ & $24.3(18.8-33.7)$ & 0.39 \\
\hline $\begin{array}{l}\text { Geriatrics } \\
\text { consultation }\end{array}$ & $27(28.4)$ & $87(74.4)$ & $<0.001$ \\
\hline $\begin{array}{l}\text { Time to geriatrics } \\
\text { consultation (h), } \\
\text { median (IQR) }\end{array}$ & $65.5(44.7-77.0)$ & $51.4(34.0-88.4)$ & 0.49 \\
\hline $\begin{array}{l}\text { Geriatric consultation } \\
\text { before surgery }\end{array}$ & $2(7.4)$ & $10(11.5)$ & 0.54 \\
\hline $\begin{array}{l}\text { Falls assessment } \\
\text { completed }\end{array}$ & $48(50.5)$ & $87(74.4)$ & $<0.001$ \\
\hline $\begin{array}{l}\text { Use of scheduled } \\
\text { acetaminophen }\end{array}$ & $92(96.8)$ & 111 (94.9) & 0.48 \\
\hline $\begin{array}{l}\text { Use of preoperative } \\
\text { peripheral nerve block }\end{array}$ & $9(9.5)$ & $22(18.8)$ & 0.06 \\
\hline $\begin{array}{l}\text { Mental status } \\
\text { assessment performed }\end{array}$ & $65(68.4)$ & $109(93.2)$ & $<0.001$ \\
\hline $\begin{array}{l}\text { Delirium prevention } \\
\text { strategies identified }\end{array}$ & 32 (33.7) & $85(72.7)$ & $<0.001$ \\
\hline $\begin{array}{l}\text { Bone health } \\
\text { assessment performed }\end{array}$ & $11(11.6)$ & $55(47.0)$ & $<0.001$ \\
\hline $\begin{array}{l}\text { Vitamin D or calcium } \\
\text { or both prescribed }\end{array}$ & $61(64.2)$ & $113(96.6)$ & $<0.001$ \\
\hline $\begin{array}{l}\text { Antiresorptive } \\
\text { prescribed or } \\
\text { recommended }\end{array}$ & $26(27.4)$ & 72 (61.5) & $<0.001$ \\
\hline \multicolumn{4}{|l|}{ Clinical outcome } \\
\hline Incidence of delirium & 25 (26.3) & $31(26.5)$ & 0.98 \\
\hline $\begin{array}{l}\text { Delirium duration (h), } \\
\text { median (IQR) }\end{array}$ & $\begin{array}{l}72.0(48.0- \\
168.0)\end{array}$ & $72.0(48.0-144.0)$ & 0.92 \\
\hline $\begin{array}{l}\text { Length of stay (d), } \\
\text { median (IQR) }\end{array}$ & $7.0(4.0-10.0)$ & $7.0(5.0-10.0)$ & 0.32 \\
\hline $\begin{array}{l}\text { In-hospital } \\
\text { mortality }\end{array}$ & $5(5.3)$ & $7(6.0)$ & 0.82 \\
\hline $\begin{array}{l}\text { Discharge to } \\
\text { long-term care }\end{array}$ & $6(6.3)$ & $10(8.6)$ & 0.54 \\
\hline $\begin{array}{l}\text { Urinary tract } \\
\text { infection }\end{array}$ & $6(6.3)$ & $4(3.4)$ & 0.32 \\
\hline $\begin{array}{l}\text { Hospital-acquired } \\
\text { pneumonia }\end{array}$ & $4(4.2)$ & $6(5.1)$ & 0.75 \\
\hline Thromboembolism & $1(1.1)$ & 0 & 0.27 \\
\hline $\begin{array}{l}\text { Acute coronary } \\
\text { syndrome }\end{array}$ & $2(2.1)$ & $7(6.0)$ & 0.16 \\
\hline
\end{tabular}

Multivariable analysis of factors predicted to be associated with delirium and length of stay using an a priori model showed that the incidence of delirium and the length of stay did not change after implementation of the orthogeriatric model (Table 3). As predicted, patients with a high comorbidity burden $(\mathrm{CCI} \geq 6 \mathrm{v} . \leq 3)$ had longer hospital stays, as did those who required ICU care. Patients transferred from the partner site had a shorter length of stay because they were repatriated postoperatively. Patients who were admitted from retirement homes required a longer hospital stay than those admitted from their own 


\begin{tabular}{|c|c|c|c|c|}
\hline \multirow[b]{2}{*}{ Factor } & \multicolumn{2}{|c|}{ Incidence of delirium } & \multicolumn{2}{|c|}{ Length of stay } \\
\hline & Adjusted OR (95\% Cl) & $p$ value & Adjusted RR (95\% CI) & $p$ value \\
\hline Postintervention v. preintervention & $0.81(0.43-1.70)$ & 0.657 & $0.98(0.89-1.07)$ & 0.58 \\
\hline Age & $1.08(1.02-1.14)$ & 0.008 & $1.01(1.01-1.02)$ & $<0.001$ \\
\hline Intraoperative nerve block & $1.14(0.41-3.19)$ & 0.806 & - & - \\
\hline General v. regional anesthesia & $1.72(0.72-4.12)$ & 0.220 & - & - \\
\hline \multicolumn{5}{|l|}{ Charlson Comorbidity Index score } \\
\hline $4-5$ v. $\leq 3$ & $1.18(0.22-6.43)$ & 0.679 & $1.07(0.88-1.29)$ & 0.51 \\
\hline$\geq 6 v . \leq 3$ & $2.07(0.35-12.30)$ & 0.230 & $1.96(1.61-2.39)$ & $<0.001$ \\
\hline Patients required ICU stay & $2.97(0.68-13.05)$ & 0.150 & $1.29(1.09-1.53)$ & 0.003 \\
\hline Patient transferred from partner site & - & - & $0.62(0.47-0.82)$ & $<0.001$ \\
\hline Patient from retirement home $\mathrm{v}$. home & - & - & $1.19(1.05-1.35)$ & 0.007 \\
\hline Patient from long-term care facility $v$. home & - & - & $0.50(0.40-0.61)$ & $<0.001$ \\
\hline
\end{tabular}

homes; the latter patients were probably more independent before hospital admission.

\section{Discussion}

Randomized controlled trials have shown that the implementation of CGAs reduces postoperative mortality, length of hospital stay and incidence of postoperative delirium in older adults with hip fracture in academic centres. ${ }^{8-12}$ We studied the implementation of an orthogeriatric collaborative care model in older adults with hip fracture in a community hospital setting. This initiative improved the rates at which key quality indicators were met, specifically in assessment of mental status, falls and bone health, identification of delirium prevention strategies, prescription of vitamin $\mathrm{D}$ or calcium or both, and recommendations for antiresorptive therapy. The incidence of delirium and hospital length of stay were unchanged.

Importantly, when our hospital implemented its orthogeriatric model the goal of conducting proactive geriatric assessment was not achieved. Only $74 \%$ of patients in the postintervention group received geriatric consultations. Factors that contributed to a lower rate of assessments may have included inconsistent use of preprinted order sets that initiated CGA referrals, the discharge of healthy patients before they were seen by the geriatrician or lack of staffing in the evening and on weekends. Additionally, time to geriatric consultation from admission did not significantly improve from an average of more than 48 hours. This suggests that patients in the postintervention group who would have required geriatric consultation in a reactive fashion did not receive substantially different treatment from that received by patients in the preintervention group. In comparison, early proactive geriatric assessments, either preoperatively or within 24 hours after surgery, have been shown to reduce delirium and length of stay in patients with hip fracture. ${ }^{16}$
Nonpharmacological delirium prevention strategies may not have been implemented effectively, as the standardized instruction set used in the postintervention period could have been overlooked. More tailored recommendations for nursing staff and visitors may be more effective.

A timelier course to geriatric assessment was identified as a key area for improvement. We hypothesize that achieving timely proactive geriatric assessments may be difficult in a community hospital without evening and weekend geriatric medicine coverage. Other studies have employed a hospitalist in the comanagement of hip fracture care, showing decreases in length of stay but no difference in mortality or complications. These studies also did not report on the effects on other key quality standards for hip fracture care. ${ }^{21,22}$ An important first step in quality improvement will be to implement standard consultations to geriatric medicine upon admission for hip fracture, rather than through a postoperative order set. Our centre, which includes 5 orthopedic surgeons, has recruited an additional geriatrician since the end of the study. A study at this community hospital with a more rigorous methodology is required, such as an interrupted time series, to evaluate outcomes as the orthogeriatric collaboration strengthens over time.

\section{Limitations}

Our study had several potential biases because of its retrospective chart review design. First, data were abstracted by a single data abstractor, who was not blinded to the study objectives. Second, the study was not immune to chronologic bias, with improved electronic documentation of discharge medications and improved electronic documentation of clinician progress notes across the study period. Sparse handwritten documentation early in the study period may have biased the preintervention group toward lower success rates in meeting quality metrics and lower rates of delirium because of omission of documentation. 
There were 2 major confounding factors that may have affected our ability to detect differences in the primary outcomes attributable to implementing an orthogeriatric care model. First, a large international multicentre randomized controlled trial called HIP-ATTACK started on Jan. 11, 2016, at this community hospital during the second half of the preintervention period. ${ }^{23}$ The trial randomly assigned patients with hip fractures that required surgical intervention to receive rapid medical clearance with targeted arrival to the operating room within 6 hours of diagnosis or to receive usual care. Patients randomly assigned to the intervention group had reduced time to surgery, although results showed no difference in mortality or in a composite of major postoperative complications. The trial's protocol for routine postoperative troponin evaluation did show in our data, with a trend toward more asymptomatic acute coronary syndromes being present in the intervention group. Second, as part of an effort to improve overall patient care on surgical wards, a nurse practitioner was hired in September 2016 (during the postintervention period) and nurses received education to use the Confusion Assessment Method daily to monitor for delirium. An increase in the number of overall assessments by the nurse practitioner and nurses as well as in the number of routine geriatric assessments in the postintervention period contributed to detection signal bias favouring increased detection of delirium. The positive effect of the orthogeriatric care model in reducing the incidence of delirium may not have been visible in our data when underdetection of delirium rates because of poor documentation in the preintervention period was accounted for.

\section{Conclusion}

Although there was no difference in the incidence of postoperative delirium and length of stay in this study, the orthogeriatric collaborative care model employed in caring for older adults with hip fracture in a community setting showed improvement in the rates at which several other key quality standards for hip fracture care were met. Earlier proactive, comprehensive geriatric assessment in a community hospital setting will be the target for further quality improvement initiatives.

Affiliations: From the University of Toronto, Toronto, Ont. (Lee, E.K.C. Wong, C.L. Wong); the Markham Stouffville Hospital, Markham, Ont. (Koo, Naqvi); Unity Health, Toronto, Ont. (E.K.C. Wong, C.L. Wong); and the Li Ka Shing Knowledge Institute, Toronto, Ont. (E.K.C. Wong, C.L. Wong).

Funding: This study was funded by a Community Innovation Award from the Canadian Orthopaedic Association.

Competing interests: None declared.

Contributors: K. Koo and C. Wong designed the study. J. Lee and R. Naqvi acquired the data, which all authors analyzed. J. Lee, K. Koo and E. Wong wrote the manuscript, which all authors critically revised. All authors gave approval of the final version to be published.
Content licence: This is an Open Access article distributed in accordance with the terms of the Creative Commons Attribution (CC BY-NC-ND 4.0) licence, which permits use, distribution and reproduction in any medium, provided that the original publication is properly cited, the use is noncommercial (i.e., research or educational use), and no modifications or adaptations are made. See: https:// creativecommons.org/licenses/by-nc-nd/4.0/

\section{References}

1. Jaglal S, Cameron C, Croxford R, et al. Ontario Osteoporosis Strategy - provincial performance data for osteoporosis management. Technical report. Ontario Osteoporosis Strategy; 2017.

2. Health Quality Ontario, Ministry of Health and Long-Term Care. Quality-based procedures: clinical handbook for hip fracture. Toronto: Health Quality Ontario; 2013. Available: www.hqontario.ca/ evidence/publications-and-ohtac-recommendations/clinical-handbooks (accessed 2019 Feb. 6).

3. Ftouh S, Morga A, Swift C. Management of hip fracture in adults: summary of NICE guidance. BM7 2011;342:d3304.

4. Mak JCS, Cameron ID, March LM. Evidence-based guidelines for the management of hip fractures in older persons: an update. Med $\mathcal{F}$ Aust 2010;192:37-41.

5. Scottish Intercollegiate Guidelines Network. Guideline 111: management of hip fracture in older people. Edinburgh: Scottish Intercollegiate Guidelines Network; 2009.

6. Mukherjee K, Brooks S, Barraco R, et al. Elderly adults with isolated hip fractures - orthogeriatric care versus standard care: a practice management guideline from the Eastern Association for the Surgery of Trauma. 7 Trauma Acute Care Surg 2020;88:266-78.

7. Waddell J, Mcglaason R, Zellermeyer V, et al. National hip fracture toolkit, Canada. Bone and Joint Canada; 2011.

8. Henderson CY, Shanahan E, Butler A, et al. Dedicated orthogeriatric service reduces hip fracture mortality. Ir $\mathcal{F}$ Med Sci 2017;186: $179-84$.

9. Grigoryan KV, Javedan H, Rudolph JL. Orthogeriatric care models and outcomes in hip fracture patients: a systematic review and metaanalysis. 7 Orthop Trauma 2014;28:e49-55.

10. Folbert EC, Hegeman JH, Vermeer M, et al. Improved 1-year mortality in elderly patients with a hip fracture following integrated orthogeriatric treatment. Osteoporos Int 2017;28:269-77.

11. Hawley S, Kassim Javaid M, Prieto-Alhambra D, et al. Clinical effectiveness of orthogeriatric and fracture liaison service models of care for hip fracture patients: population-based longitudinal study. Age Ageing 2016;45:236-42.

12. Shields L, Henderson V, Caslake R. Comprehensive geriatric assessment for prevention of delirium after hip fracture: a systematic review of randomized controlled trials. 7 Am Geriatr Soc 2017; 65:1559-65.

13. Thingstad P, Taraldsen K, Saltvedt I, et al. The long-term effect of comprehensive geriatric care on gait after hip fracture: the Trondheim Hip Fracture Trial - a randomised controlled trial. Osteoporos Int 2016;27:933-42.

14. Rubenstein LZ, Stuck AE, Siu AL, et al. Impacts of geriatric evaluation and management programs on defined outcomes: overview of the evidence. 7 Am Geriatr Soc 1991;39:8S-16S; discussion 17S-18S.

15. Wong CL, Von Maltzahn M, McFarlan A, et al. Leading best practices: emerging cross-specialty collaborative care models. CGS 7 CME. 2017;7(1).

16. Eamer G, Amir T, Sidian SC, et al. Comprehensive geriatric assessment for older people admitted to a surgical service. Cochrane Database Syst Rev 2018;1:CD012485.

17. Marcantonio ER, Flacker JM, John Wright R, et al. Reducing delirium after hip fracture: a randomized trial. $7 \mathrm{Am}$ Geriatr Soc 2001;49:516-22.

18. Soong C, Cram P, Chezar K, et al. Impact of an integrated hip fracture inpatient program on length of stay and costs. 7 Orthop Trauma 2016;30:647-52. 
19. Inouye SK, Leo-Summers L, Zhang Y, et al. A chart-based method for identification of delirium: validation compared with interviewer ratings using the confusion assessment method. 7 Am Geriatr Soc 2005;53:312-8.

20. Charlson ME, Pompei P, Ales KL, et al. A new method of classifying prognostic comorbidity in longitudinal studies: development and validation. 7 Chronic Dis 1987;40:373-83.

21. Phy MP, Vanness DJ, Melton LJ, et al. Effects of a hospitalist model on elderly patients with hip fracture. Arch Intern Med 2005;165:796801 .

22. Bracey DN, Kiymaz TC, Holst DC, et al. An orthopedic-hospitalist comanaged hip fracture service reduces inpatient length of stay. Geriatr Orthop Surg Rebabil 2016;7:171-7.

23. HIP ATTACK Investigators. Accelerated surgery versus standard care in hip fracture (HIP ATTACK): an international, randomised, controlled trial. Lancet 2020;395:698-708. 